\title{
A CONCEPÇÃO DE HOMEM NA OBRA A IDEOLOGIA ALEMÃ dE MARX E ENGELS
}

CONCEPT OF MAN IN THE WORK GERMAN IDEOLOGY BY MARX AND ENGELS

Fabiano Veliq*

\begin{abstract}
RESUMO
O presente artigo tem como objetivo abordar a questão do conceito de homem na obra $A$ ideologia alemã de Marx e Engels, e seus desdobramentos em diversos aspectos da relação homem-trabalho em Marx. A abordagem de Marx sobre a questão do homem está dispersa em vários de seus escritos. Dessa forma, nosso artigo foca na concepção de homem adotada por Marx e Engels na sua obra $A$ ideologia alemã. A discussão se inicia contextualizando aspectos do contexto de Marx e seu embate com a esquerda hegeliana; após este momento passamos a explicitar a noção de Trabalho em Marx e evidenciar como que a partir dessa noção é possível pensar o desenvolvimento de temas caros como alienação, luta de classe e comunismo. Tal análise a nosso ver se mostra importante por se tratar de um texto importante na história da filosofia e por oferecer uma perspectiva várias vezes esquecida de Marx e Engels, que é a sua preocupação com o homem e o mundo que o rodeia.
\end{abstract}

PALAVRAS-CHAVE: Marx. Trabalho. Homem. Capitalismo.

\section{ABSTRACT}

This article aims to address the question of the concept of man in the work German Ideology by Marx and Engels and its developments in various aspects of the man-work relationship in Marx. Marx's work on the question of man is dispersed in several of his writings. Thus, our article focuses on the conception of man adopted by Marx and Engels in their work German Ideology. Our article begins by contextualizing aspects of Marx's context and his clash with the Hegelian left; after this moment we started to explain the notion of Work in Marx and show how, based on this notion, it is possible to think about the development of expensive themes such as alienation, class struggle and communism. Such analysis, in our view, is important because it is an important text in the history of philosophy and because it offers a perspective that Marx and Engels often overlooked, which is his concern for man and the world around him

KEYWORDS: Marx. Work. Men. Capitalism.

\footnotetext{
* Doutor em Psicologia pela PUC Minas e doutorando em filosofia pela UFMG. Professor de filosofia da PUC Minas. E-mail: veliqs@gmail.com.
} 


\section{INTRODUÇÃO}

Karl Marx em vários de seus escritos aborda a questão do homem. Para ele, esta é uma questão crucial para desenvolver sua filosofia, e por isso ele dedica muito do seu trabalho filosófico à elucidação das relações do homem com a sociedade.

Karl Marx sem dúvida é um dos grandes filósofos do século XIX. Sua filosofia até hoje é alvo de estudos não apenas no meio filosófico, mas também no meio econômico e no político.

Karl Marx nasce em cinco de maio de 1818 em Tréveros, importante cidade da Prússia, país que exercia um forte papel na cultura da região como ponto de encontro do liberalismo revolucionário vindo da França e do conservadorismo do antigo regime, liderado pela Prússia. Neste país, na época, segundo afirma Zilles (1991, p. 120), a filosofia de Hegel tornara-se uma espécie de ideologia oficial.

Em 1836 Marx matricula-se na universidade de Berlim, capital da Prússia, e lá tem contato com o que, na história da filosofia, é conhecido como esquerda hegeliana. Começa a participar dos grupos de discussões sobre o pensamento de Hegel. Em 1841 ele defende sua tese de doutorado sobre o materialismo de Epicuro e Demócrito.

No ano de 1843 muda-se para Paris e lá conhece as ideias revolucionárias do socialismo de Fourier, de Owen e de Saint-Simon. Em Paris inicia sua amizade com Friedrich Engels e lá também desponta o seu interesse pela miséria do proletariado industrial.

Em 1845 passa a residir em Bruxelas, onde escreve com Engels algumas obras, tais como A ideologia alemã (1845), A miséria da filosofia (1847) e Manifesto comunista (1848). Expulso da Bélgica, volta à Alemanha, de onde, após a revolução de 1848, foi expulso, indo viver em Londres, tendo ali residido até o fim de sua vida. Foi nesta cidade que Marx publicou sua maior obra, $O$ capital, em 1867, na qual faz uma crítica à sociedade de sua época e mostra as relações que regem o sistema capitalista.

\section{O EMBATE COM A ESQUERDA HEGELIANA}

Como dito acima, Marx desde muito cedo tem contato e é influenciado pela filosofia hegeliana, assim como pela esquerda hegeliana, principalmente por Feuerbach, assumindo em grande parte a crítica à religião deste filósofo. $\mathrm{O}$ contato com a filosofia de Hegel se mostra 
muito importante para entender o caminho traçado por Marx, de forma que seria impossível surgir o pensamento marxiano sem as formulações hegelianas, principalmente o método dialético. A proposta hegeliana de uma história que se desenvolve dialeticamente marcará o pensamento de Marx de maneira extremamente grande, e mesmo com toda a crítica que Marx destina a Hegel não podemos deixar de ressaltar a dependência de Marx das formulações hegelianas. No entanto, Marx acusa veementemente a filosofia hegeliana de ser muito abstrata e de não se vincular a uma prática efetiva no mundo, como também critica a filosofia de Feuerbach por atribuir ao homem uma essência a-histórica. Se por um lado Marx aceita a crítica feuerbachiana da religião ao colocá-la como produção humana, por outro ele rejeita uma essência humana que não seja determinada socialmente.

Marx parte do princípio de que não é a consciência que determina a sociedade, mas é esta que determina aquela. Segundo ele, "o homem não é um ser abstrato, agachado fora do mundo. O homem é o mundo do homem, o estado, a sociedade" (MARX; ENGELS, 2008, p. 5). Portanto, ao se falar sobre o homem, deve-se falar sobre o mundo do homem.

Em seus primeiros escritos, Marx está contra todo o movimento denominado esquerda hegeliana. Marx quer mostrar que a verdadeira mudança na sociedade não se dará apenas quando os homens mudarem suas ideias a respeito das coisas, mas principalmente quando os homens começarem a alterar as suas condições materiais de vida.

\section{A OBRA A IDEOLOGIA ALEM $\tilde{A}$}

Esse texto de Marx sobre a questão do homem está disperso em vários de seus escritos. Ora, não seria possível abordar aqui toda a dimensão da reflexão que Marx dá a este respeito, uma vez que o trabalho ficaria extremamente extenso. Dessa forma, para a concepção de homem adotada por Marx, atemo-nos mais à Ideologia alemã por nela encontrar as questões mais pertinentes à questão a que se propõe este artigo.

No prefácio da Ideologia alemã Marx ilustra o movimento da esquerda hegeliana da seguinte forma:

Certa vez, um bravo homem imaginou que, se os homens se afogavam, era unicamente porque estavam possuídos pela ideia de gravidade. Se retirassem da cabeça tal representação, declarando, por exemplo, que se tratava de uma representação religiosa, supersticiosa, ficariam livres de todo perigo de afogamento. 
Durante toda sua vida, lutou contra essa ilusão da gravidade, cujas consequências perniciosas todas as estatísticas lhe mostravam, através de provas numerosas e repetidas. Esse bravo homem era o protótipo dos novos filósofos revolucionários alemães. (MARX; ENGELS, 1979, p. 18).

Para Marx, o ideal neo-hegeliano de que, uma vez trocada a consciência atual por uma consciência crítica sobre as coisas, os homens estariam livres dos grilhões que os aprisionavam não faz sentido. Para ele, o que se precisa mudar não é a consciência, mas as condições materiais de vida. Só a partir dessa mudança é que o homem poderá realmente ser livre e então mudar a história.

Marx deixa claro na Ideologia alemã que seus pressupostos são reais, i.e, indivíduos reais em seu meio de vida, nas condições reais em que se situam. Ele explicita que não adotará a linha da esquerda hegeliana, a de uma crítica da consciência, mas tomará a via empírica, a da observação das condições materiais de vida. Marx vê já nesse momento uma ausência de perspectiva em se ater à reflexão sobre o homem abstrato, sem realidade. Qualquer reflexão que não se baseie nos homens reais deveria ser deixada de lado e, segundo ele, esse era em grande medida o erro da chamada esquerda hegeliana.

O primeiro pressuposto para Marx é a existência de indivíduos humanos vivos. $\mathrm{O}$ homem se relaciona com o mundo a partir do seu corpo. Não possui uma essência abstrata através da qual se relaciona com a natureza. Mas os animais também se relacionam com a natureza e, portanto, o que diferencia o homem dos animais não seria a relação com a natureza e sim a forma como ele se relaciona com a natureza. O homem não é determinado por ela, mas é capaz de ultrapassá-la, é capaz de ir além dela. Nessa superação da natureza ele é capaz de produzir algo que os animais não conseguem: ele é capaz de produzir trabalho. A forma diferenciada pela qual o homem se relaciona com o meio é o trabalho. Vaz explica essa tese de Marx da seguinte maneira: “a produção da própria vida irá implicar no homem os predicados especificamente humanos da consciência-de-si, da intencionalidade, da linguagem, da fabricação e uso de instrumentos e da cooperação com seus semelhantes" (VAZ, 1991, p. 128).

Para Marx, o homem não cria seus meios de vida a partir do nada. Em suas palavras:

O modo pelo qual os homens produzem seus meios de vida depende, antes de tudo, da natureza dos meios de vida já encontrados e que têm de reproduzir [...] Tal como os indivíduos manifestam sua vida, assim são eles, o que eles são coincide portanto com sua produção, tanto com o que produzem, como com o modo como produzem. 
O que os indivíduos são, portanto, depende das condições materiais de sua produção. (MARX; ENGELS, 1979, p. 27).

Tomado sob este aspecto, o homem é um ser que entra em um mundo já dado, e a partir desse dado ele irá construir um mundo cujos significados serão atribuídos pelo próprio homem. A produção do homem está totalmente determinada pelas condições materiais de vida. Há uma conexão íntima entre a estrutura social e a produção.

A estrutura social e o Estado nascem constantemente do processo de vida de indivíduos determinados, mas destes indivíduos, não como podem aparecer na imaginação própria ou alheia, mas tal e como realmente são, isto é, tal e como atuam e produzem materialmente e, portanto, tal e como desenvolvem suas atividades sob limites, pressupostos e condições materiais, independentes de sua vontade. (MARX; ENGELS, 1979, p. 36).

O pensar, aquilo que chamamos espiritualidade, emana das condições materiais de vida $^{1}$. Para Marx, isso é consequência do fato de o homem ser produtor de suas representações. Dessa forma, Marx dá às representações humanas um caráter terreno e não metafísico. $\mathrm{O}$ homem produz suas representações, pois suas necessidades são pluriformes, ou seja, biológicas, psicossociais e culturais. Tais representações só são feitas porque as condições materiais de existência as exigem do homem.

Marx, ao contrário da esquerda hegeliana, faz ascender a filosofia da terra ao céu. Ele não parte do que os homens imaginam ou representam ou pensam para chegar ao homem de carne e osso, mas parte dos homens agindo no mundo e, a partir da vida real desses indivíduos, ele expõe os reflexos ideológicos do processo de sua vida. Segundo Marx,

\footnotetext{
A moral, a religião, a metafísica e qualquer outra ideologia, assim como as formas de consciência que a elas correspondem, perdem toda a aparência de autonomia. Não têm história, nem desenvolvimento; mas os homens, ao desenvolverem sua produção material e seu intercâmbio material, transformam também, com esta sua realidade, seu pensar e os produtos de seu pensar. Não é a consciência que determina a vida, mas a vida que determina a consciência. (MARX; ENGELS, 1979, p. 37).
}

\footnotetext{
1É interessante notar como que essa proposta de Marx será assimilada posteriormente pela Teologia da Libertação em sua vertente católica e protestante. Enquanto Marx vê a religião como "ópio do povo", a Teologia da Libertação verá nessa denúncia de Marx uma possibilidade para o engajamento na luta pelos mais pobres. Essa virada realizada pela Teologia da Libertação marca em grande medida o aspecto paradoxal com o qual a religião católica e protestante recebe o marxismo no pós-guerra. Para uma análise dessa apropriação realizada pela Teologia, permita-me remeter o leitor ao nosso texto Dizer e viver a esperança: aspectos sobre linguagem e religião no pensamento de Rubem Alves (VELIQ, 2014).
} 
A condição de determinação da consciência pela vida é a "linguagem da vida real". A relação, portanto, entre a consciência e a linguagem é causal. Os homens criam conceitos e pensam a partir de suas condições materiais.

Como as leis da consciência são as leis da linguagem, e tais leis são determinadas pela organização social, a consciência do homem é determinada pela organização social.

\begin{abstract}
A linguagem é tão antiga quanto a consciência real, prática, que existe para os outros homens, e, portanto, existe também para mim mesmo; e a linguagem nasce, como a consciência, da carência da necessidade de intercâmbio com outros homens [...]. [A] consciência, portanto, é desde o início um produto social, e continuará sendo enquanto existirem homens. (MARX; ENGELS, 1979, p. 43).
\end{abstract}

A consciência enquanto efeito das relações sociais é alterada à medida que o homem se relaciona com outros homens e com o mundo na história. Como afirma Fromm (1964, p. 36), “a História é a história da autorrealização do homem; ela nada mais é que a autocriação do homem por intermédio de seu próprio trabalho e produção".

O homem só vive enquanto homem quando é capaz de produzir seu mundo. Essa produção que é a chave do fazer-se humano. A especificidade do homem está em um tipo de produção visando alcançar o objeto do seu desejo. Enquanto o animal é a sua atividade, o homem desenvolve uma atividade que visa um objeto de sua vontade e é consciente dela. $\mathrm{O}$ homem se caracteriza por uma atividade vital consciente e, segundo Marx, é essa atividade vital que o coloca como ente-espécie e como ser livre. Enquanto o animal apenas se ajusta à natureza, tirando dela o estritamente necessário para se manter vivo, o homem produz o que quer, fruto da sua liberdade e da sua indeterminabilidade. Ele produz algo para além da natureza. Ele produz não apenas visando sua adequação, mas produz de forma universal. Esta universalidade da produção do homem pode ser tida como universal porque é superação da condição determinada pela natureza.

Em Marx, o homem se realiza quando vê seu trabalho externado em algo para além de si mesmo. É no processo produtivo que o homem se realiza enquanto homem. E essa produção deve-se dar de forma ativa, não meramente de forma mecânica. Ela é um impulso criador visando a alcançar o seu objetivo.

Como afirma Fromm (1964, p. 101), ao explicar Marx: 
É no trabalho exercido no mundo objetivo que o homem realmente se comprova como um ente-espécie. Essa produção é sua vida ativa como espécie; graças a ela, a natureza aparece como trabalho e realidade dele. O objetivo do trabalho, portanto, é a objetificação da vida como espécie do homem, pois ele não mais se reproduz a si mesmo apenas intelectualmente, como na consciência, mas ativamente e em sentido real, e vê seu próprio reflexo em um mundo por ele construído.

Pode-se notar que o homem em Marx é visto como um ser que está em contato com a natureza, dela depende, mas ao mesmo tempo dela se distingue através de uma produção que supera a dos animais por visar não apenas a adequação à natureza, mas a superação desta para alcançar o objeto de seu desejo.

No entanto, com a criação da propriedade privada e a divisão do trabalho, este último deixa de ser expressão do homem e passa a ter uma existência à parte. O produto do trabalho passa a ser um objeto estranho ao homem, passa a dominá-lo de forma a tornar-se uma força independente de quem a produz. O produto do trabalho deve ser uma objetivação do próprio homem. No entanto, no modo de produção capitalista, o trabalho do homem não é mais extensão dele, a diferença entre o homem e o objeto de seu trabalho se efetiva de forma mais clara. Aquilo que é produção do homem adquire um status para além dele. Trabalhar deixa de fazer parte da natureza do trabalhador; este enquanto trabalha não exterioriza seus sentimentos, sua criatividade, não se realiza, mas antes se nega, sofre e negligencia o seu status de humano e se transforma em mero meio para a produção de algo ${ }^{2}$. Sua atividade não é extensão sua, mas aparece a ele como algo alheio, não pertencente a ele e, portanto, desprovido de significação humana. Esse tipo de trabalho torna o homem escravo dos meios de produção. De senhor da natureza (Bacon), ele se transforma em escravo da produção.

Inspirando-se em Kant, Marx refraseia a segunda formulação do imperativo categórico, segundo a qual o homem sempre deve ser um fim em si mesmo e nunca um meio para um fim. Como afirma Kant (2009, p. 28),

Agora digo: o homem, e em geral todo ser racional, existe como fim em si, não apenas como meio, do qual esta ou aquela vontade possa dispor a seu talento; mas, em todos os seus atos, tanto nos que se referem a ele próprio, como nos que se

2 É extremamente interessante pensar como que essa denúncia de Marx vai-se tornando cada vez mais escancarada na ideologia contemporânea, mas pelo fato de estar à mostra constantemente, passa por normalidade. O que se percebe é o grande esforço das propagandas de não revelar esse caráter do trabalho alienado ressaltando sempre um possível amalgamento entre o sujeito e sua produção, mesmo que cada vez mais dificilmente isso de fato ocorra. No capitalismo do século XXI a própria servidão é vista como privilégio. Nesse sentido recomendamos a obra de Antunes (2018). 
referem a outros seres racionais, ele deve sempre ser considerado ao mesmo tempo como fim.

Ao se tornar meio para a produção, o homem sai de sua condição de humano e abre mão de seu poder criador frente à natureza. A esse processo, Marx dá o nome de alienação. Nesse sentido, muito além de ser apenas mais um modo de produção, percebe-se que a crítica de Marx se dá em um ponto muito mais fundamental que apenas o socioeconômico. A alienação nesse sentido é uma desumanização, pois fere a própria dignidade do ser humano. A alienação em Marx se refere a um sistema de relações socioeconômicas que independem da consciência para existir; ela é objetiva, fruto das condições sociais.

Como afirma Fischer (1970, p. 31-32),

\begin{abstract}
A partir da divisão do trabalho, com todas as suas consequências (propriedade privada dos meios e dos produtos do trabalho, domínio do produto sobre o produtor), o conjunto das forças produtivas e instituições - Estado, igreja, justiça, etc. - colocase diante dos indivíduos como poderes estranhos, surgindo assim a condição designada por Marx como alienação. Os homens (exceto uma minoria ínfima com atividade criadora) não se reconhecem em suas próprias obras; a produção social existe como fatalidade exterior a eles, a criação eleva-se acima do criador e essa "segunda" natureza, desviada da natureza originária e elementar, aparece ainda mais poderosa, ainda menos passível de direção e controle do que a primeira. [...] A relação objetiva escapou aos indivíduos e se tornou um poder autônomo.
\end{abstract}

O processo de alienação acaba por perverter todos os valores do homem. Este se torna cada dia mais pobre enquanto homem, pois cada vez mais está preocupado em ganhar dinheiro para poder usufruir de bens de consumo, e se torna novamente escravo do sistema criado por ele mesmo.

Essa é a condição da alienação a que Marx se refere. O homem que deveria ser o senhor se torna escravo, e nessa relação se desumaniza. O trabalhador, ao produzir, acaba por criar uma "entidade" independente de si e que se opõe a ele, uma vez que retira o caráter produtivo do seu trabalho. Nas palavras de Marx e Engels (1979, p. 104):

A única relação que os indivíduos ainda mantêm com as forças produtivas e com sua própria existência - o trabalho - perdeu para eles toda a aparência de autoatividade e só conserva sua vida atrofiando-a [...]. [A] vida material, o trabalho, aparece como meio. 
O que Marx propõe para resolver essa solução é uma reumanização do trabalho que resgate o aspecto criador do homem e o faça ser novamente humano.

Para que tal reumanização ocorra, será preciso que a causa de tal processo seja combatida. Ao fazer a análise da situação histórica em que se encontra, Marx constata que, na realidade, o segredo do produto está na prática de quem o produziu. Na oitava tese de Marx sobre Feuerbach se lê: “Toda vida social é essencialmente prática. Todos os mistérios que levam a teoria para o misticismo encontram sua solução racional na práxis humana e na compreensão dessa práxis" (MARX; ENGELS, 1979, p. 128).

Se o homem é um ser da práxis, e ela produz um objeto que para ele é um poder estranho, a chave para a compreensão da alienação no campo da práxis é saber a quem pertence tal produto. Marx conclui que tal produto pertence a um ser diferente do homem que o produziu, pertence a um outro, que deverá ser um outro homem que, consequentemente, será diferente do trabalhador. A partir do conceito de alienação, chega-se à divisão apontada por Marx entre os detentores do capital e os detentores da mão-de-obra. Essa divisão é a condição de possibilidade da alienação.

O homem, portanto, se vê preso a um sistema que ele mesmo produziu e, no entanto, não consegue sair dele. Marx afirma que no desenvolvimento das forças produtivas chega-se a uma fase em que essas forças não são mais produtivas e sim destrutivas, e graças a isso exacerba-se a divisão entre duas classes ${ }^{3}$. A classe que detém o capital, i.e, detém os meios de produção - os capitalistas - e a classe do proletariado que detém a força de trabalho, mas não detém os meios de produção - representada pelos operários. Esta segunda classe referida suporta todos os encargos da sociedade sem aproveitar as vantagens propiciadas por ela. Essa classe engloba a maior parte da sociedade, e é dela que emana o desejo por uma "revolução radical". A percepção desse fato é a primeira condição para tal revolução que, necessariamente, se dará contra a classe dominante. Toda a história caminha baseada na dinâmica da luta de classes.

A revolução comunista proposta por Marx alteraria as condições da produção, ela teria o objetivo de superar a própria divisão em classes, uma vez que é feita por quem mais sofre

3 Algo que precisa ser apontado é que em Marx a ideia de Luta de Classes é uma questão estrutural e não apenas algo que surge no modo de produção capitalista. A Luta de Classes se dá assim como "motor da história". Aqui nós podemos entender novamente o quanto a filosofia hegeliana influencia a proposta de Marx do ponto de vista da estrutura. É perfeitamente possível ler a noção de Luta de Classes em Marx a partir do próprio movimento dialético hegeliano em que Proletariado e Capitalista se mostram como "universalidade" e "particularidade" na qual a negação da particularidade gerará a singularidade da sociedade comunista. 
com a referida divisão. Tal revolução possibilitaria ao homem derrubar o modo de produção capitalista e fundar a sociedade sobre uma nova base.

\section{CONCLUSÃO}

Podemos observar que em Marx a revolução tem um caráter utópico. O homem deseja sair da condição alienada e viver em um lugar onde seu trabalho seja uma extensão dele próprio. Em Marx podemos perceber uma crença de que o futuro será a superação do passado e do presente. A consciência se libertaria da condição alienada, na qual de fato se encontra, e se lançaria rumo a uma nova condição, a da liberdade. Tal libertação, para Marx, se daria a partir de uma revolução que terminaria com o advento da sociedade comunista, em que a divisão de trabalho não seria mais necessária, o trabalho teria recuperado o seu caráter como exteriorização do humano, como atividade humana criadora. O trabalho no comunismo não seria alienado e isso possibilitaria o advento do homem em sua totalidade. Como afirma Fischer (1970, p. 13), "esse comunismo antevisto por Marx era para ele a verdadeira supressão do conflito entre o homem e a natureza e do homem com o homem". Superado tal conflito, o homem estaria livre para se realizar como homem.

\section{REFERÊNCIAS}

ANTUNES, Ricardo. O privilégio da servidão: o novo proletariado de serviços na era digital. São Paulo: Boitempo, 2018.

MARX, Karl; ENGELS, Friedrich. A ideologia alemã. 2. ed. São Paulo: Editora Ciências Humanas, 1979.

MARX, Karl; ENGELS, Friedrich. Introdução à crítica da filosofia do direito de Hegel. Tradução Artur Morão. Covilhã: Lusosofia Press, 2008. Disponível em: http://www.lusosofia.net/textos/marx_karl_para_a_critica_da_filosofia_do_direito_de_hegel.p df. Acesso em: 17 jan. 2011. Título original: Zur Kritik der Hegelschen Rechtsphilosophie.

FISCHER, Ernst. O que Marx realmente disse. Rio de Janeiro: Civilização Brasileira, 1970.

FROMM, Erich. O conceito marxista de homem. Rio de Janeiro: Zahar Editores, 1964.

KANT, Imannuel. Fundamentação da metafísica dos costumes. Lisboa. Editora 70, 2009.

VAZ, Henrique C. de Lima. Antropologia filosófica I. São Paulo: Loyola, 1991. 
VELIQ, Fabiano. Dizer e viver a esperança: aspectos sobre linguagem e religião no pensamento de Rubem Alves. REFLEXUS, Vitória, ES, ano VIII, n. 12, 2/2014.

ZILLES, Urbano. Filosofia da religião. 2. ed. São Paulo: Paulus, 1991. 